\title{
The quest for medicines, a grand challenge in the twenty-first century
}

\section{Theophile Godfraind*}

Laboratoire de Pharmacologie, Faculté de Médecine, Université Catholique de Louvain, Brussels, Belgium

*Correspondence: theophile.godfraind@uclouvain.be

It is reported by primatologists that Great Apes utilize various plants for their healing effects (Sumner, 2000; Halberstein, 2005). Chimpanzees swallow the leaves of several plants including leaves of Ficus exasperata, which contain a potent psoralen that kills nematode worms. Leaves are not the only plant parts that might be used by animals. Chimpanzees also chew the bitter pith from young shoots of the species Vernonia containing steroid-glycosides interfering with the life cycle of trematodes causing schistosomiasis. Interestingly, Vernonia is known in Tanzania as mujonso (the bitter leaf tree). Natives of Tanzania are crushing Vernonia leafs and twigs in cold water to treat pain associated with intestinal parasites. There are several other examples of the use by Humans of extracts of plants also used by Great Apes. This is not surprising in view of the encyclopedic knowledge collected by Nganga through traditional observation of their natural environment (Godfraind, 2010). It is likely that the quest for medicines is an early activity of humanity. Indeed oldest written documents report on medicines preparations initially orally transmitted from generation to generation. For instance the Ebers papyrus, one of the oldest known medical works dated about $1550 \mathrm{BC}$, is a compilation of medical texts including remedies originated years ago. It is not the purpose of this paper to review history of empirical discoveries of medicines mostly prepared from plants. They occurred in various continents as shown by collections of materia medica reported by Chinese, Greek and Latin authors in the BC era (Wang et al., 2007). Interestingly, in the nineteenth century, François Magendie and Claude Bernard, studying alkaloids extracted from traditional poisons from Africa or South America, observed that the action of those agents had a precise anatomical localization (Lazorthes and Campan, 1984). Those studies mark the birth of Experimental Pharmacology at the time of chemical purification of active molecules from plant extracts (Godfraind, 2007). A subsequent step has been the transformation of natural molecules, native of different regions, into better-tolerated preparations such as aspirin obtained by acetylating sodium salicylate. During the first half of the twentieth century, Ernest Fourneau and his Colleagues (including Daniel Bovet and Frederico Nitti) of the Pasteur Institute in Paris produced derivatives of adrenaline, acetylcholine and histamine as well as of their natural antagonists, giving rise to study of their pharmacological properties (Bovet and Bovet-Nitti, 1948). This research trend culminated in Sir James Black's discoveries of $\beta$-blockers and $\mathrm{H}_{2}$ antagonists (Black, 1979). Some of those molecules have been used in experiments designed to verify Clark's receptor theory leading to the observation that the action of drugs does obey the law of mass action (Kenakin, 2004). The development of quantitative bioassay by J.H. Burn (Vane, 1982) and the initiation of analytical pharmacology by H.O. Schild (Arunlakshana and Schild, 1959) paralleled studies reported above. They proved to be useful for the finding of other pharmacological principles including ACE inhibitors (Cushman and Ondetti, 1991) and Calcium Channel Blockers (Godfraind et al., 1986), an illustration of the role of Pharmacology in drug discovery (Fredholm et al., 2002).

Despite huge investment in novel technology and attempts to streamline the drug discovery process, the last 10 years or so have not seen any increase in the number of new pharmacological entities that have reached the market. This low rate of success is one of the reasons why the estimated cost for $\mathrm{RD}$ of a new drug is so very high, around $900 \mathrm{mil}-$ lions Euro (Donnelly and Jehenson, 2005), the other reason is that costs increase faster than inflation. The constantly increasing cost for research and development and the relatively steady trickle of new drugs to the market has been known for quite some time. This has obviously worried drug industry.
Attempts to correct the imbalance have included various purportedly cost-cutting mergers and the pursuit of blockbuster drugs. New lead-identification methodologies such as combinatorial chemistry and high-throughput screening have been integrated into pharmaceutical research. At the end of the twentieth century from 1950 onwards, a period of pharmaceutical success in drugs for cardiovascular, gastroenterological and neurological diseases, novel chemical entities were evaluated on composite models in organ bath or test tube before going to whole animals or Humans. Expert teams could reach production and evaluation of about 2000 molecules per year. For the new methodologies, composite models have been abandoned to study 2000 compounds per day, which means 400,000 per year. From 2000, robots operate up to $10^{5}$ tests or even more per day on cloned targets. These measures have caused a remarkable uniformity in industry something that is further enhanced by the use of essentially identical research techniques (Schirlin et al., 2007). The clear lack of success of these managerial techniques must be recognized. Would the introduction of concepts such as "translational medicine" or "systems biology" bring a proper evaluation of those molecules designed at random and tested on artificial targets? The hypothesis that understanding of biological systems will somehow emerge from huge arrays of data and sophisticated statistical analyses does not take into account the complexity of natural processes. The chase of universal blockbuster drugs has found its limits in the field of cancer therapy with monoclonal antibodies, when it was observed that trastuzumab was active in breast cancers expressing HER2 (Crowder et al., 2004), therefore requiring a genomic classification of patients. Quite recently, studies on BRAF-mutant melanoma (Bollag et al., 2010) emphasized pharmacogenomic approach of patients' therapy. This reinforces the need for developing translational 
medicine (Godfraind, 2007). From the Basic Pharmacology point of view, molecular design from target structure looks more rational than a random search in a library of $10^{6}$ compounds. But we should not forget from where we are coming. Indeed, natural substances are not only active by themselves but they appear to be lead compounds for a large family of medicines, a nice example is the large family of derivatives of penicillin. According to some estimates, Earth is home for about 250,000 different species of plants, for up to 30 million species of insects and for an equal number of species of fungi, algae, and bacteria. However, when not provided by empirics, very little number of these organisms has been tested to see whether they harbor bioactive substances. Recently important small molecules such as artemisinin and shikimic acid, the precursor of oseltamivir (Tamiflu ${ }^{\circledR}$ ), have been purified from natural products of millenary use in China. Screening of the huge library of natural products is an immense task but it will further Pharmacology. Since we are entering the time of the omics and of personalized medicine, finding cellular targets of small molecules is a major breakthrough in drug discovery as illustrated by the case of cyclo-oxygenase target of aspirin (Vane et al., 1990). The development of biomarkers for predictive toxicity and for identifying the nature of diseases and their evolution under drug treatment is mandatory (see Grand Challenges of Chief Editors of Specialty Journals of Frontiers in Pharmacology). Here academia and industry should cooperate and this must be done at a translational level, in a twoway road (Marincola, 2003). Frontiers in Pharmacology Journals welcome publications related to those novel aspects of drug research as well as analytical studies of classically used drugs.

\section{REFERENCES}

Arunlakshana, O., and Schild, H. O. (1959). Some quantitative uses of drug antagonists. Br. J. Pharmacol. Chemother. 14, 48-58.

Black, J. W. (1979). Propranolol and cimetidine. Verh. K Acad. Geneeskd. Belg. 41, 166-172.

Bollag, G., Hirth, P., Tsai, J., Zhang, J., Ibrahim, P.N., Cho, H., Spevak, W., Zhang, C., Zhang, Y., Habets, G., Burton, E. A., Wong, B., Tsang, G., West, B. L., Powell, B., Shellooe, R., Marimuthu, A., Nguyen, H., Zhang, K. Y., Artis, D. R., Schlessinger, J., Su, F., Higgins, B., Iyer, R., D’Andrea, K., Koehler, A., Stumm, M., Lin, P. S., Lee, R. J., Grippo, J., Puzanov, I., Kim, K. B., Ribas, A., McArthur, G. A., Sosman, J. A., Chapman, P. B., Flaherty, K. T., Xu, X., Nathanson, K. L., and Nolop, K. (2010). Clinical efficacy of a RAF inhibitor needs broad target blockade in BRAFmutant melanoma. Nature 467, 596-599.

Bovet, D., and Bovet-Nitti, F. (1948). Structure et Activite Pharmacodynamique des Médicaments du Système Nerveux Végétatif. Bâle-New York: S. Karger.

Crowder, R. J., Lombardi, D. P., and Ellis, M. J. (2004). Successful targeting of ErbB2 receptors-is PTEN the key? Cancer Cell 6, 103-104.

Cushman,D.W., and Ondetti, M.A. (1991). History of the design of captopril and related inhibitors of angiotensin converting enzyme. Hypertension 17, 589-592.

Donnelly, F., and Jehenson, P. (2005). European technology platform on innovative medicines. Int. J. Pharm. Med. 19, 153-161.

Fredholm, B. B., Fleming, W. W., Vanhoutte, P. M., and Godfraind, T. (2002). The role of pharmacology in drug discovery. Nat. Rev. Drug Discov. 1, 237-238.
Godfraind, T. (2007). [Traditional and translational medicine]. Bull. Acad. Natl. Med. 191, 715-725; discussion 725-726.

Godfraind,T.(2010).A propos des médecines traditionnelles en Afrique Centrale. Rev. Quest. Sci. 181, 341-371.

Godfraind, T., Miller, R., and Wibo, M. (1986). Calcium antagonism and calcium entry blockade. Pharmacol. Rev. 38, 321-416.

Halberstein, R. A. (2005). Medicinal plants: historical and cross-cultural usage patterns. Ann. Epidemiol. 15, 686-699.

Kenakin, T. (2004). Principles: receptor theory in pharmacology. Trends Pharmacol. Sci. 25, 186-192.

Lazorthes, G., and Campan, L. (1984). [Francois Magendie (1783-1855)]. Bull. Acad. Natl. Med. 168, 105-111.

Marincola, F. M. (2003). Translational medicine: a twoway road. J. Transl. Med. 1, 1.

Schirlin, D., Galvan, M., and Le Fur, G. (2007). [New methods in pharmaceutical research: combinatorial chemistry and high throughput screening]. Bull. Acad. Natl. Med. 191, 727-736; discussion 736-737.

Sumner, J. (2000). The Natural History of Medicinal Plants. Portland/London: Timber Press.

Vane, J. R. (1982). J.H. Burn: an appreciation. Br. J. Pharmacol. 75, 3-7.

Vane, J. R., Flower, R. J., and Botting, R. M. (1990). History of aspirin and its mechanism of action. Stroke 21, IV12-23.

Wang, M. W., Hao, X., and Chen, K. (2007). Biological screening of natural products and drug innovation in China. Philos. Trans. R. Soc. Lond., B. Biol. Sci. 362, 1093-1105.

Received: 20 October 2010; accepted: 25 October 2010; published online: 22 November 2010.

Citation: Godfraind $T$ (2010) The quest for medicines, a grand challenge in the twenty-first century. Front. Pharmacol. 1:134. doi: 10.3389/fphar.2010.00134

Copyright (C) 2010 Godfraind. This is an open-access article subject to an exclusive license agreement between the authors and the Frontiers Research Foundation, which permits unrestricted use, distribution, and reproduction in any medium, provided the original authors and source are credited. 